\title{
Influence of strong preformed particle gels on low permeable formations in mature reservoirs
}

\author{
Mahmoud O. Elsharafi ${ }^{1} \cdot$ Baojun Bai $^{2}$
}

Received: 4 March 2015/Published online: 6 January 2016

(C) The Author(s) 2015. This article is published with open access at Springerlink.com

\begin{abstract}
In mature reservoirs, the success of preformed particle gel (PPG) treatment rests primarily on the ability of the PPG to reduce and/or plug the high permeable formations, but not damage the low permeable formations. Static test models (filtration test model and pressure test model) were used to determine the effect of PPG on low permeable formations. This work used a strong preformed particle gel, Daqing (DQ) gel made by a Chinese company. The particle gel sizes were ranged from 30 to 120 mesh for this work. PPGs are sized in a millimeter or micrometer, which can absorb over a hundred times their weight in liquids. The gel strength was approximately $6500 \mathrm{~Pa}$ for a completely swollen PPG with $1 \%$ (weight percentage) $\mathrm{NaCl}$ solution (brine). $0.05 \%, 1 \%$, and $10 \% \mathrm{NaCl}$ solutions were used in experiments. Sandstone core permeability was measured before and after PPG treatments. The relationship between cumulative filtration volumes versus filtration times was determined. The results indicate that DQ gels of a particle size of 30-80 mesh did not damage the cores of a low permeability of 3-25 $\mathrm{mD}$. The DQ gels of a smaller particle size ranging from 100 to 120 mesh damaged the core and a cake was formed on the core surface. The results also indicate that more damage occurred when a high load pressure (400 psi) was applied on the high permeability cores (290-310 mD). The penetration of the particle gels
\end{abstract}

Mahmoud O. Elsharafi

mahmoud.elsharafi@mwsu.edu

1 McCoy School of Engineering, Midwestern State University, Wichita Falls, TX 76308, USA

2 Department of Geological Sciences \& Engineering, Missouri University of Science and Technology, Rolla, MO 65409, USA

Edited by Yan-Hua Sun into the low permeable formations can be decreased by the best selection of gel types, particle sizes, and brine concentrations.

Keywords Formation damage - Mature reservoirs . Preformed particle gel · Low permeable formations

\section{Introduction}

Water production is the main problem in oil/gas well operations as reservoirs mature (Seright 2003; Bai et al. 2008). Veil et al. (2004) reported that nearing the end of oil/gas production lives, water production can be $98 \%$ of the material brought to the surface. Water production makes oil/gas wells unproductive and economically wasteful, which can cause early shut-in wells and decreased oil/gas production. Also, more water production can increase the costs of removing both scale and corrosion, and separating water from hydrocarbon. These costs increase as the water production increases (Dalrymple 1997). Worldwide, approximately three barrels of water are produced daily with each barrel of oil (Wiedeman 1996; Bailey et al. 2000). The situation is even worse in the United States, where more than 10 barrels of water are produced for each barrel of oil (Nemec 2014). Bailey et al. (2000) reported that the cost of treating and removing the surplus water production is expected to be 40 billion U.S. dollars (USD) globally. Hence, conformance control treatments and water shut-off are important in the oil industry.

Fluid flow in porous media is affected by the reservoir heterogeneity. It affects the selection of production plans, reservoir management, and oil recovery methods. Reservoir heterogeneity is the most important cause of increased water production and decreased oil production. Water 
flooding is widely used in the oil industry to maintain reservoir pressure. Numerous reservoirs have cracks and channels due to mineral dissolution or sand production in the duration of water flooding (Liu et al. 2010). Reservoirs with high permeability zones and fractures are relatively common in mature reservoirs (Bai et al. 2008; Liu et al. 2010). To solve the problem of reservoir heterogeneity, gel treatments are widely used in oilfields (Zitha and Darwish 1999; Thomas et al. 2000; Bai et al. 2007a, b; Wang et al. 2008; Al-Muntasheri and Zitha 2009; Wu et al. 2011).

A chemical method extensively uses in situ gel treatment for both water shut-off and conformance control. In the in situ gel treatment process, a mixture of polymer and cross-linker (gelant, the liquid formulation of the in situ gel composition is called a gelant) is injected into the formation, and the gel forms under reservoir conditions (Liu et al. 2010). In situ gel penetrates into the high permeable formation and creates gel to reduce or plug the high permeable formation. Therefore, the gel is affected by the rock and fluid properties. Preformed particle gels (PPGs) are used to overcome different drawbacks inevitable in in situ gelation systems. These drawbacks include the inability to control gelation time, the uncertainty of gelling due to shear degradation, gelant composition changes caused by chromatographic fractionation effect and dilution by formation water. PPG is created on the surface and injected as gel particles (Chauveteau et al. 2001; Pritchett et al. 2003; Frampton et al. 2004; Rousseau et al. 2005; Sydansk et al. 2005; Bai et al. 2007a, b; Zaitoun et al. 2007; Wu et al. 2011). PPGs are a better selection than in situ gels from the point of controlling the particle sizes for different reservoir characterization. Presently, preformed gels contain preformed bulk gels, partially preformed gels, and particle gels (Chauveteau et al. 2000, 2001; Bai et al. 2007a, b, 2008).

For conformance control treatments, all particle gels used in oilfields are superabsorbent polymers (SAP). Particle gels contain PPGs, microgels, swelling micrometersized polymers (Bright Water ${ }^{\mathrm{R}}$ ), and a $\mathrm{pH}$-sensitive crosslinked polymer (Coste et al. 2000; Chauveteau et al. 2000, 2001; Al-Anaza and Sharma 2002; Pritchett et al. 2003; Frampton et al. 2004; Huh et al. 2005; Rousseau et al. 2005; Bai et al. 2007a, b, 2008; Zaitoun et al. 2007; Roussennac and Tosschi 2010; Zhang et al. 2010; Jia et al. 2011; Juntail et al. 2011a, b). Table 1 displays different types of particle gels used in the oil industry, related studies and the researchers who developed these gels, particle size, and applications. PPGs, microgels, and BrightWater ${ }^{\mathrm{R}}$ have all been used as water shut-off materials in mature reservoirs. $\mathrm{pH}$-sensitive polymers are used to solve potential problems caused by polymer flooding, such as high injection pressure with associated pumping costs, the creation of unwanted injection well fractures, and the mechanical degradation of polymers due to high shear near the wellbore (Al-Anaza and
Sharma 2002; Huh et al. 2005, 2009; Al-Muntasheri et al. 2009,2010 ). During matrix acidizing treatments for in situgelled acids, numerous acid methods have been used to improve acid diversion in heterogeneous reservoirs (Gomaa and Naser-El-Din 2010; Gomaa et al. 2011; Rabie et al. 2011, 2012; Reddy 2014). Legemah et al. (2014) reported the impact of different crosslinkers on the fluid properties while using low polymer loading as fracturing fluids.

PPGs have a collection of compositions which could absorb more than a hundred times their weight in solutions (Bai et al. 2007a, b, 2008; Zhang and Bai 2011; James 2011). In addition, they do not easily release the absorbed fluids under pressure (Bai et al. 2007a, b, 2008; Zhang and Bai 2011; James 2011). Bai et al. (2012) reported that the PPGs could absorb an enormous quantity of water because water has a large quantity of hydrogen ions. The water absorption volume is affected by sodium chloride $(\mathrm{NaCl})$ concentrations (Bai et al. 2012). Sun et al. (2014) reported that the main element of PPG is the potassium salt of a cross-linked polyacrylic acid/polyacrylamide copolymer.

Liu et al. (2010) reported that in China, PPGs are widely used to decrease the theft zones in production and/or injection wells. Lately, to control $\mathrm{CO}_{2}$ breakthrough for $\mathrm{CO}_{2}$-flooded zones, both Occidental Oil Company and Kinder-Morgan Company used similar materials with good results (Smith et al. 2006; Pyziak and Smith 2007; Larkin and Creel 2008).

A lot of researchers have studied the propagation and blocking effectiveness of PPGs in both high permeable reservoirs and fractured layers (Bai et al. 2007a, b; Zhang and Bai 2011). Elsharafi and Bai (2012) determined that the best PPG treatments occurred when the PPG could simply penetrate through the high permeable layers without damaging the low permeable formations. Elsharafi and Bai (2015) found that the permeability of the gel pack in the fluid channels depended upon the particle strength, particle size, brine concentration, and the load pressure. The relationship among the cumulative injection volumes against time is needed to determine the damage to low permeable reservoirs (Ershaghi et al. 1986; Vetter et al. 1987). The cumulative injection volume value was used because if the core were damaged the flow rate will not be constant. As a result, the curves (the relationship between the cumulative filtration volume and the injection time) will not be straight lines. Filtration tests have been used in the past to study the damage of cores fully saturated with brine, oil, or residual oil while injecting suspended particles, oily water, or a combination of both into these cores (Hsi et al. 1994; Coleman and McLelland 1994; Al-Abduwani et al. 2005; Ali et al. 2009). The main purpose of this paper is to study the effect of strong PPGs on low permeable zones/areas in mature reservoirs, including the effects of rock permeability, salinity, particle size of PPGs, PPG types, pore throat size in cores, gel strength, and the injection pump 
Table 1 Various particle gels used in the oil industry

\begin{tabular}{|c|c|c|c|c|}
\hline Particle gels & Related studies & Developer & Particle size & Applications \\
\hline $\begin{array}{l}\text { Preformed } \\
\text { particle gel } \\
\text { (PPG) }\end{array}$ & $\begin{array}{l}\text { Coste et al. (2000), Bai et al. (2007a, b, 2008), Jia et al. (2011), } \\
\text { Zhang and Bai (2011), Juntail et al. (2011a, b) }\end{array}$ & $\begin{array}{l}\text { PetroChina and } \\
\text { Missouri S\&T }\end{array}$ & $\begin{array}{l}\text { Millimeter } \\
\quad(10 \mu \mathrm{m}- \\
\mathrm{mms})\end{array}$ & $\begin{array}{l}4000 \text { plus } \\
\text { injection } \\
\text { wells }\end{array}$ \\
\hline Microgels & $\begin{array}{l}\text { Chauveteau et al. (2000, 2001), Rousseau et al. (2005), Zaitoun } \\
\text { et al. (2007) }\end{array}$ & IFP & $\begin{array}{l}\text { Microgel } \\
\qquad(1-10 \mu \mathrm{m})\end{array}$ & $\begin{array}{l}10 \text { plus gas } \\
\text { wells }\end{array}$ \\
\hline Bright water ${ }^{\mathrm{R}}$ & $\begin{array}{l}\text { Pritchett et al. (2003), Frampton et al. (2004), Roussennac and } \\
\text { Toschi (2010) }\end{array}$ & $\begin{array}{l}\text { Nalco, Chevron, } \\
\text { and BP }\end{array}$ & $\begin{array}{r}\text { Submicron } \\
(<1 \mu \mathrm{m})\end{array}$ & $\begin{array}{l}60 \text { plus } \\
\text { injectors }\end{array}$ \\
\hline
\end{tabular}

pressure. This paper is also needed to find out how to minimize the formation damage when the PPGs were used for water shut-off or conformance control treatment in mature reservoirs. This work used both filtration tests and load pressure tests to find out if the PPGs will damage the low permeable zones/areas. The damage or penetration caused by PPGs on unswept low permeability oil-rich zones could be effectively controlled by controlling particle gel strength, gel type, particle size, and brine concentration. This paper's results can be used to properly select the gel particles that will not damage the formation for the best particle gel treatment.

\section{Experimental}

\subsection{Materials}

\subsubsection{Performed particle gel}

Daqing (DQ) gel, a type of preformed particle gel (PPG), was used in all filtration tests and load pressure experiments. Table 2 lists the typical characteristics of the DQ gel. The percentage in Table 2 for gel and $\mathrm{NaCl}$ are weight percent. We used gels of various particle sizes of 30 , 50-60, 80, and 100-120 mesh to determine the influence of PPG sizes on the reduction in the formation permeability. Figure 1 illustrates different particle sizes of the DQ gel fully swollen with $1 \%$ brine.

\subsubsection{Sodium chloride solutions (brines)}

Brines used in all filtration tests and load pressure experiments were prepared by dissolving sodium chloride $(\mathrm{NaCl})$

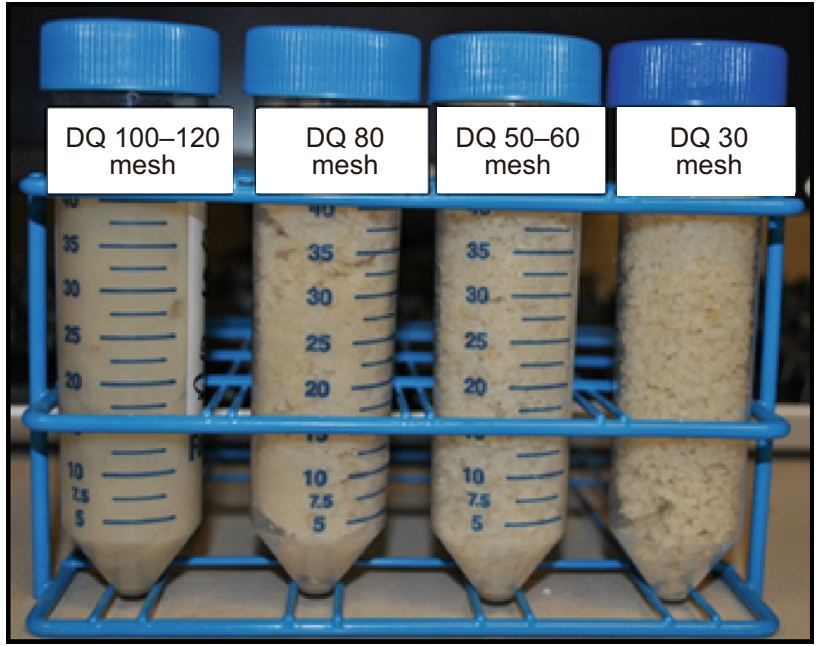

Fig. 1 Different particle sizes of the DQ gel fully swollen with $1 \%$ brine

in deionized water. Different $\mathrm{NaCl}$ solutions $(0.05,1$, and $10 \mathrm{wt} \% \mathrm{NaCl}$ solutions at laboratory conditions) were carefully chosen to make preformed particle gels. The $\mathrm{NaCl}$ concentration expressively influences the swelling ratio and the strength of PPGs. Figure 2 illustrates the influence of the $\mathrm{NaCl}$ concentration on the ultimate swelling ratio of PPGs. Table 3 indicates the PPG strength variance at different $\mathrm{NaCl}$ concentrations before and after being compressed.

\subsubsection{Sandstone core preparation}

Twenty samples were collected from different sandstone sources (Missouri sandstone, Roubidoux sandstone, and Berea sandstone). The length $(L)$ of all samples was $1.5 \mathrm{in}$. $(3.7 \mathrm{~cm})$ and the diameter $(d)$ of all samples was $1.5 \mathrm{in}$.
Table 2 Typical characteristics of the DQ gel (after Zhang and Bai 2011)

\begin{tabular}{ll}
\hline Properties & Value \\
\hline Absorption deionized water, g/g & $>15$ \\
Apparent bulk density, g/L & 850 \\
Moisture content, \% & 0.96 \\
$\mathrm{pH}$ value & $6.5-7.0( \pm 0.5 ; 1 \%$ gel in $0.9 \%$ brine $)$ \\
\hline
\end{tabular}




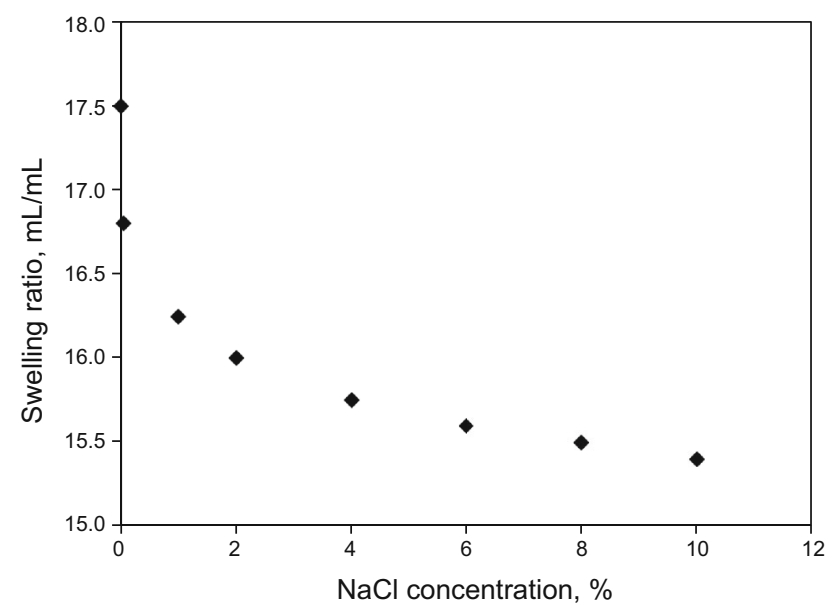

Fig. 2 Effect of the $\mathrm{NaCl}$ concentration on the swelling ratio of PPGs

$(3.7 \mathrm{~cm})$. To make sure that the dimensions of all samples were exact, a caliper was used to measure the core length and diameter. The samples were placed in an oven at $120{ }^{\circ} \mathrm{C}$ for $24 \mathrm{~h}$. After that, the samples were evacuated and then saturated to $100 \%$ with brines of chosen concentrations.

\subsection{Experimental setup}

\subsubsection{Filtration test model}

Figure 3 displays an experiment setup, which was primarily composed of a Teledyne ISCO model 500D syringe pump and one filtration test model. The syringe pump was used to inject brine into the filtration test model. The filtration test model was set up with a transparent round tube that contains a core sample fixed inside the round tube by two O-rings. In addition, a heavy duty glue was used to seal the space between the round tube and the core sample. Two lids were used (one above the round tube and one below the round tube). Bolts, nuts, and shims were used to fasten the two lids on the round tube. The first lid above the round tube had a hole which represented an inlet for the injected brine. The second lid, which was located below the round tube, had a hole which represented an outlet to discharge brine. To measure the pressures around both the sandstone

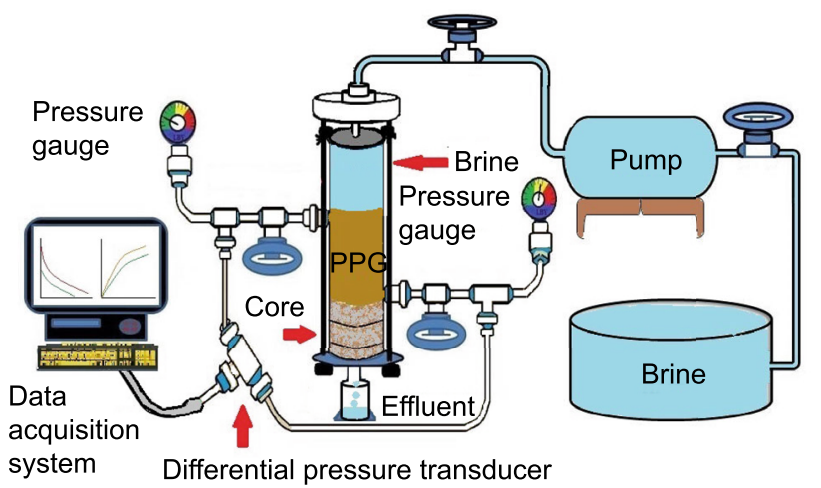

Fig. 3 Schematic of the filtration test model

core and the PPG sample, pressure gauges were used. A differential pressure transducer was attached to the data acquisition unit to measure the differential pressure around the gel pack. The filtration test model did not use a piston.

\subsubsection{Load pressure model}

Figure 4 displays a load pressure model which was used to determine the influence of PPGs on the core damage after being compressed by a piston. The difference between this model and the filtration test model is that the load pressure model used a piston. The piston was placed on the top of PPGs inside the round tube. Brine was used to fill the space above the piston inside the round tube. To measure the pressure on the bottom of the piston (load pressure), two pressure gauges were used, one under the piston and another above the sandstone core. A differential pressure transducer was connected between the two pressure gauges to measure the differential pressure around the PPG sample.

\subsection{Experimental procedures}

\subsubsection{Filtration test}

The sandstone core sample was evacuated and saturated with the desired brine, and then the porosity of the sandstone core sample $(\phi)$ was determined. The desired sandstone core sample was fixed on the bottom portion of the transparent filtration test model. Brine was injected into the

Table 3 Effect of the $\mathrm{NaCl}$ concentration on PPG strength before and after being compressed

\begin{tabular}{lllllll}
\hline $\begin{array}{l}\text { No. } \\
\text { Type of }\end{array}$ & $\begin{array}{l}\text { Particle } \\
\text { size, mesh }\end{array}$ & Gap, mm & $\begin{array}{l}\text { NaCl } \\
\text { concentration, \% }\end{array}$ & $\begin{array}{l}\text { PPG strength before being } \\
\text { compressed } G_{\mathrm{b}}^{\prime}, \mathrm{Pa}\end{array}$ & $\begin{array}{l}\text { PPG strength after being } \\
\text { compressed } G_{\mathrm{a}}^{\prime}, \text { Pa }\end{array}$ \\
\hline 1 & DQ gel & 30 & 1.5 & 0.05 & 4089 & 5994 \\
2 & DQ gel & 30 & 1.5 & 0.25 & 4328 & 6358 \\
3 & DQ gel & 30 & 1.5 & 1 & 4486 & 6583 \\
4 & DQ gel & 30 & 1.5 & 10 & 4603 & 7368 \\
\hline
\end{tabular}




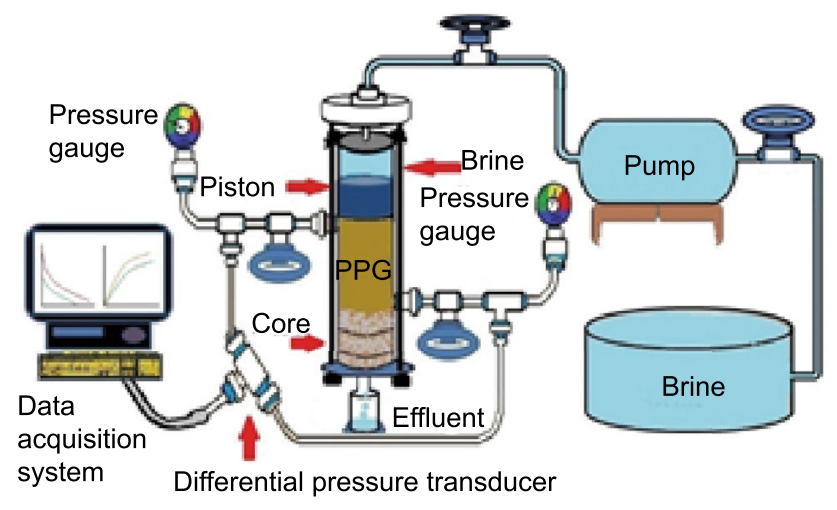

Fig. 4 Schematic of the load pressure model

filtration model to determine the core permeability before filtration tests. Completely swollen PPGs were poured into approximately half of the transparent round tube on the top of the core surface and the other space inside the round tube was filled with brine. Brine was injected at different constant pressures of 10, 50,10,100,10, 200, 10, 400, 10 psi, and each constant pressure was run for $30 \mathrm{~min}$ as shown in Table 4, or until $500 \mathrm{~mL}$ of brine (pump volume) was injected into the core sample. The reason for repeating the 10 psi pressure test, was to find out the further damage to the sandstone core sample while using various injection pressures. A cumulative flow rate was measured at 1, 2, 3, $4,5,7.5,10,15,20,25$, and $30 \mathrm{~min}$ for each pressure used. After $4 \mathrm{~h}$ and $30 \mathrm{~min}$ from the first core permeability measurements, PPGs were poured out from the round tube and brine was injected to determine the permeability of the core sample.

\subsubsection{Load pressure test}

A round piston was placed on the top of the PPGs inside the round tube after each filtration test. The PPGs were compacted by the round piston using brine as an injection liquid, with up to 300 psi pump pressure. Compacted PPGs

Table 4 Steps for various injection pressures versus time

\begin{tabular}{lrl}
\hline Step & Injection pressure, psi & Time, min \\
\hline 1 & 10 & 30 \\
2 & 50 & 30 \\
3 & 10 & 30 \\
4 & 100 & 30 \\
5 & 10 & 30 \\
6 & 200 & 30 \\
7 & 10 & 30 \\
8 & 400 & 30 \\
9 & 10 & 30 \\
\hline
\end{tabular}

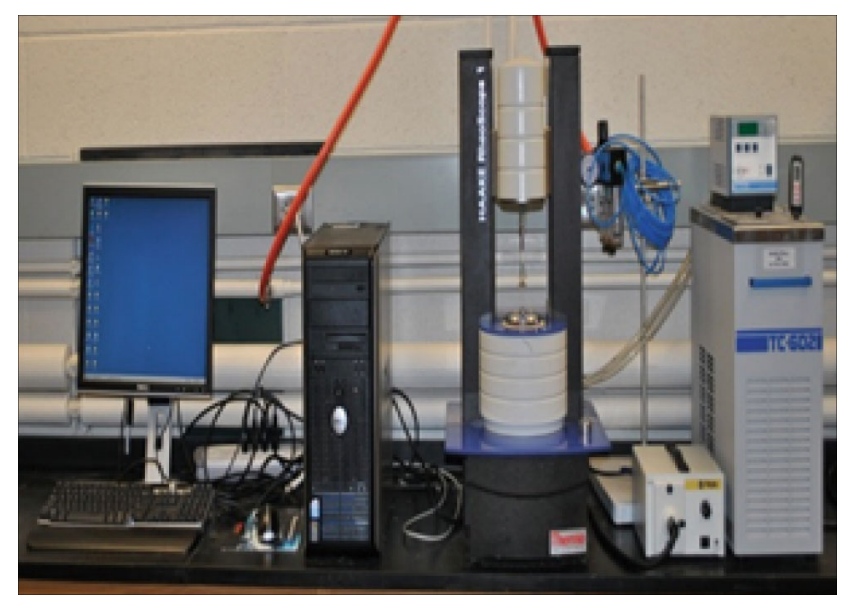

Fig. 5 Instrument for measuring gel strength

were poured out from the round tube, and brine was injected to measure the permeability of the core sample.

\subsection{Measurement of PPG strength}

Gel strength measurements were important. Particle gel strength measurements were taken to determine the PPG strength. These measurements indicated which particle gel was a weak gel and which was strong. These measurements also were used to determine which PPG could be selected without damaging the unswept oil-bearing zone. To determine the PPG strength $\left(G^{\prime}\right)$, a rheometer, KAAKE RheoScope1 (Thermo Scientific) was used as shown in Fig. 5. PPG strength measurements were taken, before and after the PPG was compacted by the piston at room temperature to find out the influence of compression on the PPG strength. The measurement model was fixed for oscillations with a frequency of $1.000 \mathrm{~Hz}$, and stress of 1.0 Pa. The sensor which was used for gel strength measurement was PP35 Ti Po LO2 016, with a gap of $1.5 \mathrm{~mm}$. PPG strength measurements were measured for each PPG sample during $60 \mathrm{~s}$.

\section{Calculation}

\subsection{Permeability of sandstone rocks}

The linear Darcy equation was used to calculate the permeability $(k)$ of different sandstone samples as shown in Eq. (1):

$k=\frac{Q \mu L}{0.78 d^{2} \Delta p}$,

where $Q$ is the fluid flow rate, $\mathrm{cm}^{3} / \mathrm{s} ; \mu$ is the brine viscosity, $\mathrm{cP} ; L$ is the sandstone core length, $\mathrm{cm} ; \Delta p$ is the differential pressure, atm; $d$ is the diameter of the 
sandstone core, $\mathrm{cm}$; and the physical meaning of the constant 0.78 is $\pi / 4$.

\subsection{Pore throat of sandstone rocks}

Numerous attempts have been made to relate the pore diameter of a solid to intrinsic, more readily measurable properties, such as porosity and permeability (Elgmati et al. 2011). The Kozeny model describes the flow of fluids across straight cylindrical channels in a rock bed by combining Darcy's and Poiseuille's laws (Elgmati et al. 2011). This study used a calculation method to find out the average pore throat size $\left(d_{\mathrm{o}}\right)$ of the various sandstone core samples. The relationship between the porosity, sandstone rock permeability, and the average pore throat diameter could be described by Eq. (2) (Hong 1985; Lei et al. 2010):

$d_{\mathrm{o}}=\sqrt{\frac{32 \tau k}{\phi}}$,

where $k$ is the sandstone rock permeability, $\mu \mathrm{m}^{2} ; \phi$ is the sandstone rock porosity, $\%$; and $\tau$ is the tortuosity constant, dimensionless. This analysis assumes that the tortuosity coefficient is equal to 1 . The pore diameter of the sandstone core sample was calculated with the simplified Kozeny formula. Table 5 shows the PPG sizes and the ratio of the particle diameter to the pore throat diameter of different samples $\left(d_{\mathrm{p}} / d_{\mathrm{o}}\right)$. The $d_{\mathrm{p}} / d_{\mathrm{o}}$ values are 84-390, 26-127, and 17-84 for the core samples of permeability of 5-25, 110-115, and 290-310, respectively.

\section{Results and discussion}

\subsection{Results of filtration tests}

The results included the influence of particle size of PPGs, core permeability, and $\mathrm{NaCl}$ concentration on the damage to different sandstone core samples. The outcomes also contained the alteration of each core permeability after gel injection. Altered constant injection pressures were used to determine the relationship between the various cumulative volumes against time (filtration curves). The curve shape could be used to find out the sandstone rock damage.

\subsubsection{Influence of PPG particle size}

Several PPGs (30, 50-60, 80, and 100-120 mesh) were used to determine the influence of particle size on sandstone rock damage.

Figure 6 shows experimental results of the cumulative filtration volume versus the filtration time. The permeabilities of various cores were $10.65 \mathrm{mD}$ for Fig. 6a, $20.45 \mathrm{mD}$ for Fig. 6b, $12.35 \mathrm{mD}$ for Fig. 6c, and $9.75 \mathrm{mD}$

Table 5 Properties of each sandstone sample used in experiments with various PPG sizes and $\mathrm{NaCl}$ solutions

\begin{tabular}{|c|c|c|c|c|c|c|c|c|}
\hline No. & Type of sandstone & Porosity $\phi, \%$ & Permeability $k, \mathrm{mD}$ & $\mathrm{NaCl}$ concentration, $\%$ & $d_{\mathrm{p}}$, mesh & $d_{\mathrm{p}}, \mu \mathrm{m}$ & $d_{\mathrm{o}}, \mu \mathrm{m}$ & $d_{\mathrm{p}} / d_{\mathrm{o}}$ \\
\hline 1 & Missouri sandstone & 14.0 & 10.65 & 1 & 30 & 595 & 1.55 & 383.84 \\
\hline 2 & Berea sandstone & 15.0 & 20.45 & 1 & $50-60$ & $250-297$ & 2.07 & $120.77-143.47$ \\
\hline 3 & Berea sandstone & 15.0 & 12.35 & 1 & 80 & 177 & 1.61 & 109.75 \\
\hline 4 & Missouri sandstone & 14.0 & 9.75 & 1 & $100-120$ & $125-149$ & 1.48 & $84.45-100.67$ \\
\hline 5 & Roubidoux sandstone & 16.0 & 114.20 & 1 & 30 & 595 & 4.74 & 125.30 \\
\hline 6 & Roubidoux sandstone & 16.0 & 111.80 & 1 & $50-60$ & 273 & 4.69 & 53.21 \\
\hline 7 & Roubidoux sandstone & 16.0 & 110.00 & 1 & $100-120$ & 137 & 4.66 & 26.82 \\
\hline 8 & Roubidoux sandstone & 18.5 & 306.00 & 1 & 30 & 595 & 7.22 & 82.31 \\
\hline 9 & Roubidoux sandstone & 18.5 & 300.28 & 1 & $50-60$ & $250-297$ & 7.16 & $34.91-41.48$ \\
\hline 10 & Roubidoux sandstone & 18.5 & 294.22 & 1 & 80 & 177 & 7.08 & 24.97 \\
\hline 11 & Roubidoux sandstone & 18.5 & 293.20 & 1 & $100-120$ & $125-149$ & 7.07 & $17.68-21.07$ \\
\hline 12 & Berea sandstone & 14.0 & 10.80 & 0.05 & 30 & 595 & 1.56 & 381.16 \\
\hline 13 & Berea sandstone & 14.0 & 10.65 & 1 & 30 & 595 & 1.55 & 383.84 \\
\hline 14 & Berea sandstone & 14.0 & 10.35 & 10 & 30 & 595 & 1.52 & 389.37 \\
\hline 15 & Roubidoux sandstone & 16.0 & 111.80 & 0.05 & 30 & 595 & 4.69 & 126.64 \\
\hline 16 & Roubidoux sandstone & 16.0 & 113.23 & 1 & 30 & 595 & 4.72 & 125.84 \\
\hline 17 & Roubidoux sandstone & 16.0 & 114.70 & 10 & 30 & 595 & 4.75 & 125.03 \\
\hline 18 & Roubidoux sandstone & 18.5 & 300.50 & 0.05 & 30 & 595 & 7.16 & 83.06 \\
\hline 19 & Roubidoux sandstone & 18.5 & 306.00 & 1 & 30 & 595 & 7.22 & 82.31 \\
\hline 20 & Roubidoux sandstone & 18.5 & 305.00 & 10 & 30 & 595 & 7.21 & 82.44 \\
\hline
\end{tabular}



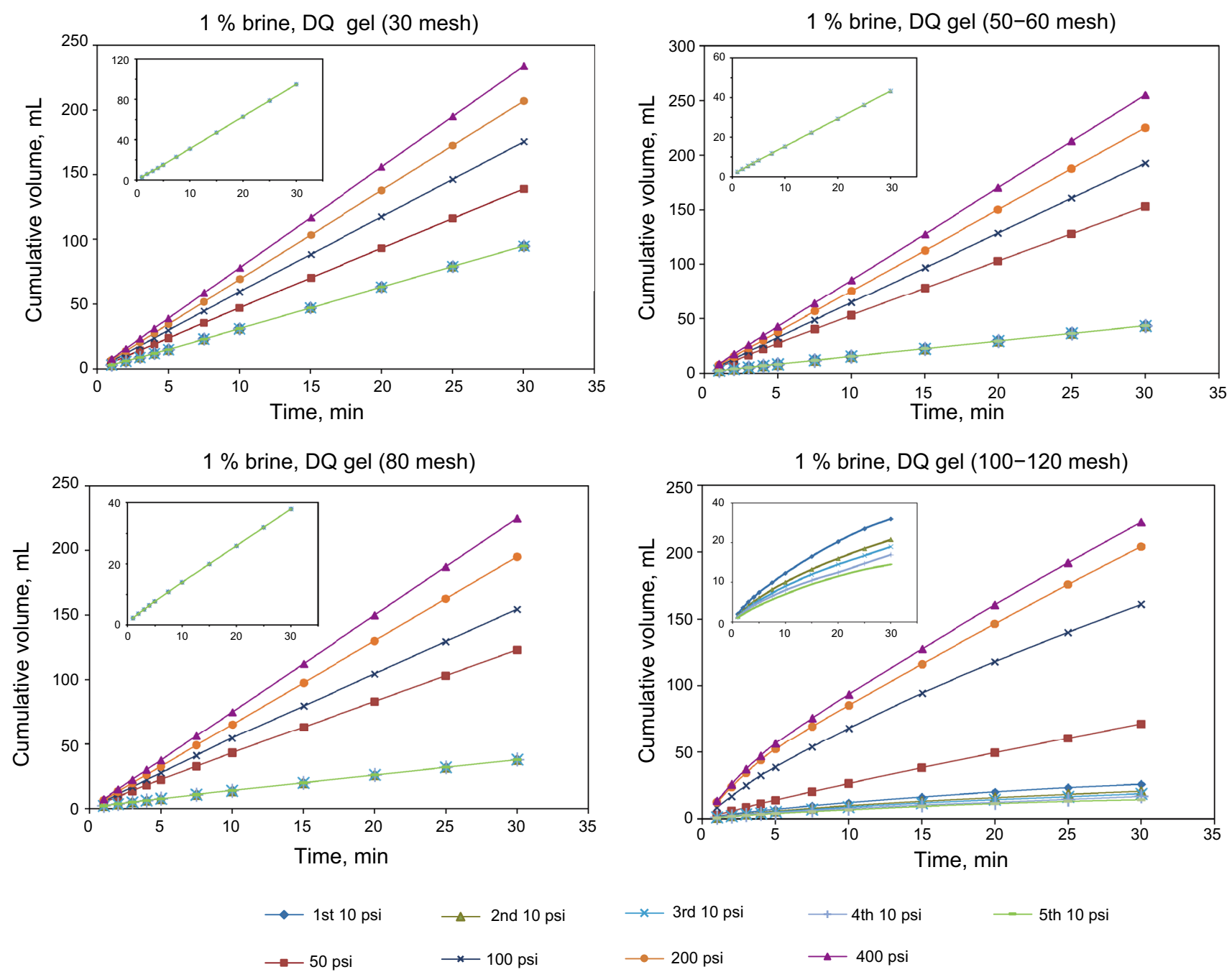

Fig. 6 Filtration test results at $1 \%$ brine. a 30 mesh PPG, $10.65 \mathrm{mD}$ core. b 50-60 mesh PPG, $20.45 \mathrm{mD}$ core. c 80 mesh PPG, $12.35 \mathrm{mD}$ core. d 100-120 mesh PPG, $9.75 \mathrm{mD}$ core

for Fig. 6d. Figure 6a, b, and c respectively, show the influence of various PPG particle sizes (30, 50-60, and 80 mesh) on the core damage using different injection pressures $(50,100,200$, and $400 \mathrm{psi})$.

The relationships between the cumulative filtration volumes and the filtration test times (filtration curves) for each 10 psi, displayed in inserts Fig. 6a-c remain a straight line. There was a change in the $y$-scale (cumulative volume) for Fig. 6a-d because of different permeabilities of PPG packs. The PPG of larger particle sizes has higher PPG pack permeability than PPG of smaller particle sizes. As a result, the flow rate was affected by the PPG pack permeability. The flow rate decreased with a decrease in the particle size. The flow rate was constant with time, which indicates that the swollen particle gels of 30, 50-60, and 80 mesh did not damage the porous media. No PPG was observed to penetrate into the cores because the particle size of PPGs was larger than the pore throat of the cores (no piston used). As a result, no cake was formed on the surface of the sandstone core. Other filtration curves in these figures remain straight lines. That means that the flow rates did not change with time and, therefore, no damage occurred at high pressures of 50,100, 200, and $400 \mathrm{psi}$. The filtration model included a round tube withstanding a maximum pressure of 400 psi. The round tube will be broken if the pressure exceeds the limit pressure. The curve shapes of the different $10 \mathrm{psi}$ pressures proved that when the injection pressure increased, no sandstone core damage occurred because all 10 psi pressure curves remain overlaid.

Figure 6d shows the influence of 100-120 mesh PPGs on the core damage. The curves are not similar for all 10 psi pressure. The filtration curves at 50,100, 200, and 400 psi did not remain linear, implying that the core damage occurred at those pressures. DQ particle gel of small sizes of 100-120 mesh may damage the sandstone cores of 
Table 6 Experimental results for the DQ gel with several particle sizes and $\mathrm{NaCl}$ solutions for filtration tests and load pressure models

\begin{tabular}{|c|c|c|c|c|c|c|c|c|c|}
\hline No. & Type of sandstone & $\phi, \%$ & $k_{\mathrm{b}}, \mathrm{mD}$ & PPG particle size, mesh & $\mathrm{NaCl}$ concentration, $\%$ & $k_{\mathrm{a}}, \mathrm{mD}$ & $K_{\mathrm{R}}, \%$ & $k_{\mathrm{ac}}, \mathrm{mD}$ & $K_{\text {Rac }}, \%$ \\
\hline 1 & Missouri sandstone & 14.0 & 10.65 & 30 & 1 & 10.65 & 0 & 5.65 & 46.94 \\
\hline 2 & Berea sandstone & 15.0 & 20.45 & $50-60$ & 1 & 20.45 & 0 & 8.50 & 58.43 \\
\hline 3 & Berea sandstone & 15.0 & 12.35 & 80 & 1 & 12.35 & 0 & 5.05 & 59.10 \\
\hline 4 & Missouri sandstone & 14.0 & 9.75 & $100-120$ & 1 & 6.65 & 31.79 & 3.75 & 61.50 \\
\hline 5 & Roubidoux sandstone & 16.0 & 114.20 & 30 & 1 & 113.90 & 0.26 & 7.07 & 93.75 \\
\hline 6 & Roubidoux sandstone & 16.0 & 111.80 & $50-60$ & 1 & 110.26 & 1.37 & 5.09 & 95.40 \\
\hline 7 & Roubidoux sandstone & 16.0 & 110.00 & $100-120$ & 1 & 30.55 & 72.27 & 3.90 & 96.45 \\
\hline 8 & Roubidoux sandstone & 18.5 & 306.00 & 30 & 1 & 304.00 & 0.65 & 0.84 & 99.70 \\
\hline 9 & Roubidoux sandstone & 18.5 & 300.28 & $50-60$ & 1 & 295.60 & 1.56 & 0.77 & 99.74 \\
\hline 10 & Roubidoux sandstone & 18.5 & 294.22 & 80 & 1 & 288.40 & 1.97 & 0.62 & 99.78 \\
\hline 11 & Roubidoux sandstone & 18.5 & 293.20 & $100-120$ & 1 & 20.70 & 92.93 & 0.36 & 99.87 \\
\hline 12 & Berea sandstone & 14.0 & 10.80 & 30 & 0.05 & 10.80 & 0 & 5.05 & 53.24 \\
\hline 13 & Berea sandstone & 14.0 & 10.65 & 30 & 1 & 10.65 & 0 & 5.65 & 46.94 \\
\hline 14 & Berea sandstone & 14.0 & 10.35 & 30 & 10 & 10.35 & 0 & 5.75 & 44.44 \\
\hline 15 & Roubidoux sandstone & 16.0 & 111.80 & 30 & 0.05 & 111.37 & 0.38 & 5.35 & 95.19 \\
\hline 16 & Roubidoux sandstone & 16.0 & 113.23 & 30 & 1 & 112.90 & 0.29 & 7.07 & 93.73 \\
\hline 17 & Roubidoux sandstone & 16.0 & 114.70 & 30 & 10 & 114.50 & 0.17 & 8.25 & 92.79 \\
\hline 18 & Roubidoux sandstone & 18.5 & 300.50 & 30 & 0.05 & 298.00 & 0.84 & 0.64 & 99.78 \\
\hline 19 & Roubidoux sandstone & 18.5 & 306.00 & 30 & 1 & 304.00 & 0.65 & 0.84 & 99.72 \\
\hline 20 & Roubidoux sandstone & 18.5 & 305.00 & 30 & 10 & 303.50 & 0.49 & 0.90 & 99.70 \\
\hline
\end{tabular}

permeability of 5-10 $\mathrm{mD}$. PPGs were observed in the core because PPGs of 100-120 mesh have a lower gel strength.

\subsubsection{Influence of core permeability}

Twenty cores of permeabilities of 5-25, 110-115, and 290-310 $\mathrm{mD}$ were selected to investigate the influence of core permeability on sandstone core damage, and experimental results are listed in Table 6.

Table 6 provides the influence of permeability on the reduction in the core permeability $\left(K_{\mathrm{R}}\right)$. The permeability reduction means the decreasing of the original core permeability in percentage value after the core was damaged by PPGs for both static and load pressure models. $k_{\mathrm{b}}$ is the core permeability before PPG usage and $k_{\mathrm{a}}$ is the core permeability after PPG usage (without a piston). Table 6 also shows the permeability of each core $\left(k_{\mathrm{ac}}\right)$ and the core permeability reduction $\left(K_{\mathrm{Rac}}\right)$ after PPGs were compressed by a piston. The core permeability was determined at flow rates of 1,2 , and $3 \mathrm{~mL} / \mathrm{min}$ after PPGs were poured out from the round tube.

For low permeability cores of $5-25 \mathrm{mD}$, the core permeability was not changed when PPGs of 30, 50-60, and 80 mesh were used. Less PPGs penetrated into the sandstone cores when PPGs of large particle sizes were used in low permeability cores. Figure 7 shows the influence of core permeability on the permeability reduction of sandstone cores under the conditions of different PPG particle sizes and brine concentrations, respectively.

The core permeability reduced by $0.26 \%-1.97 \%$ for cores of $110-310 \mathrm{mD}$ when PPGs of $30,50-60$, and 80 mesh were used. On the contrary, the core permeability increase caused an increase in the influence of 100-120 mesh PPGs on the rock damage. The core permeability reduction increased from $31.8 \%$ to $92.9 \%$ for cores of 5-310 mD.

\subsubsection{Influence of $\mathrm{NaCl}$ concentration}

Different brines $(0.05 \%, 1 \%$, and $10 \% \mathrm{NaCl}$ solutions) were chosen and used to investigate the influence of the $\mathrm{NaCl}$ concentration on the core damage. Several completely swollen PPGs were prepared from 30 mesh PPGs and different brines. As also shown in Fig. 7b, PPGs did not damage the low permeability cores $(10-15 \mathrm{mD})$ at different $\mathrm{NaCl}$ concentrations. Figure $7 \mathrm{~b}$ also shows the effect of different brine concentrations on the permeability reduction of higher permeability cores $(110-115 \mathrm{mD}$ and 300-310 mD). More core permeability reduction occurred when the $\mathrm{NaCl}$ concentration was lower for filtration tests before the gel was compressed by a piston. Table 3 shows the gel strength of the PPGs swollen with different brines 

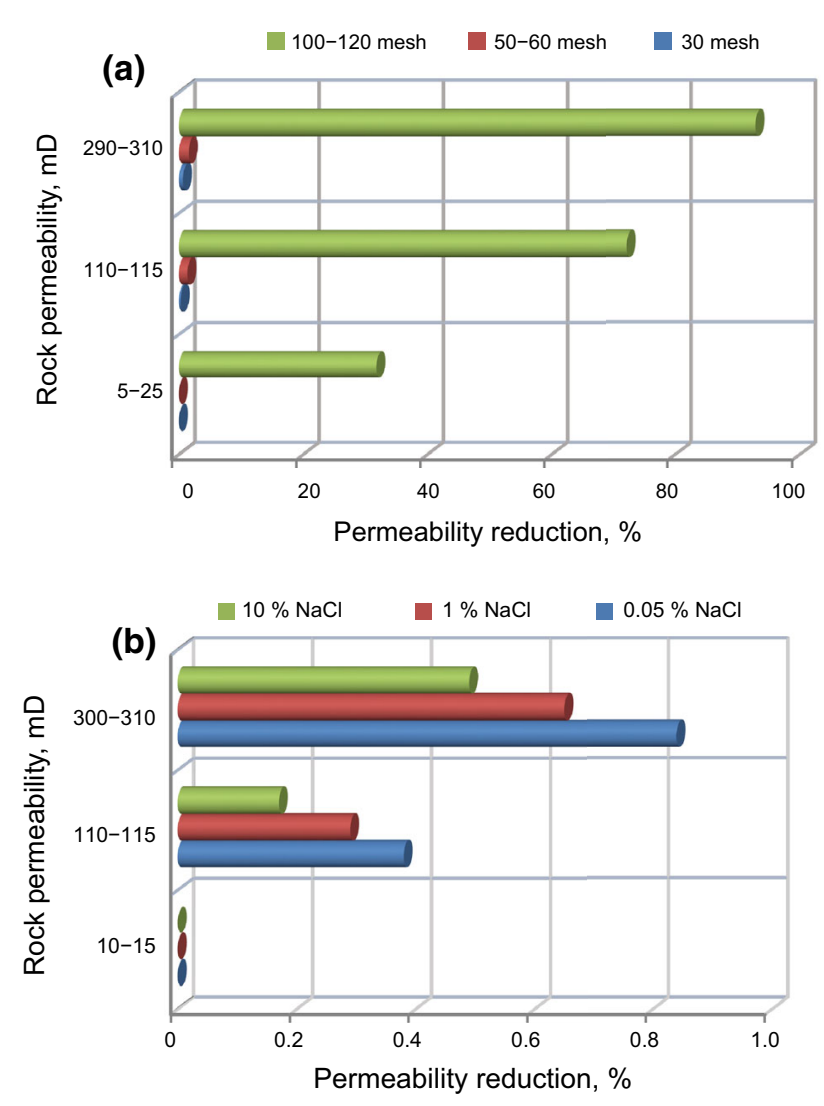

Fig. 7 Influence of core permeability on permeability reduction. a PPGs of different particle sizes (1\% brine). b Different $\mathrm{NaCl}$ concentrations (30 mesh PPGs)

before and after the gels were compressed by a piston. The PPGs with low $\mathrm{NaCl}$ concentrations have less gel strength. $G_{\mathrm{b}}^{\prime}$ was the gel strength before PPGs were compacted by a round piston and $G_{\mathrm{a}}^{\prime}$ was the gel strength after PPGs were compressed by a piston. After being compressed by a round piston, the PPG strength increased. The increase in the PPG strength was due to the water loss of swollen PPGs (Elsharafi and Bai 2012).

\subsection{Results of load pressure tests}

Sequences of experiments were done to study the influence of load pressure on rock damage as shown in Table 6. A round piston was placed at the top of the PPGs inside the round tube and the PPGs were compacted by the piston with 300 psi as a load pressure. After the gel was compressed, the permeability of each core was determined at the flow rates of $0.5,0.75$, and $1 \mathrm{~mL} / \mathrm{min}$. These lower flow rates were used because the stabilized pressure around the sandstone core increased so much after the gel was compressed and the core was damaged further. To confirm the level to which the injection pressure influenced the damage
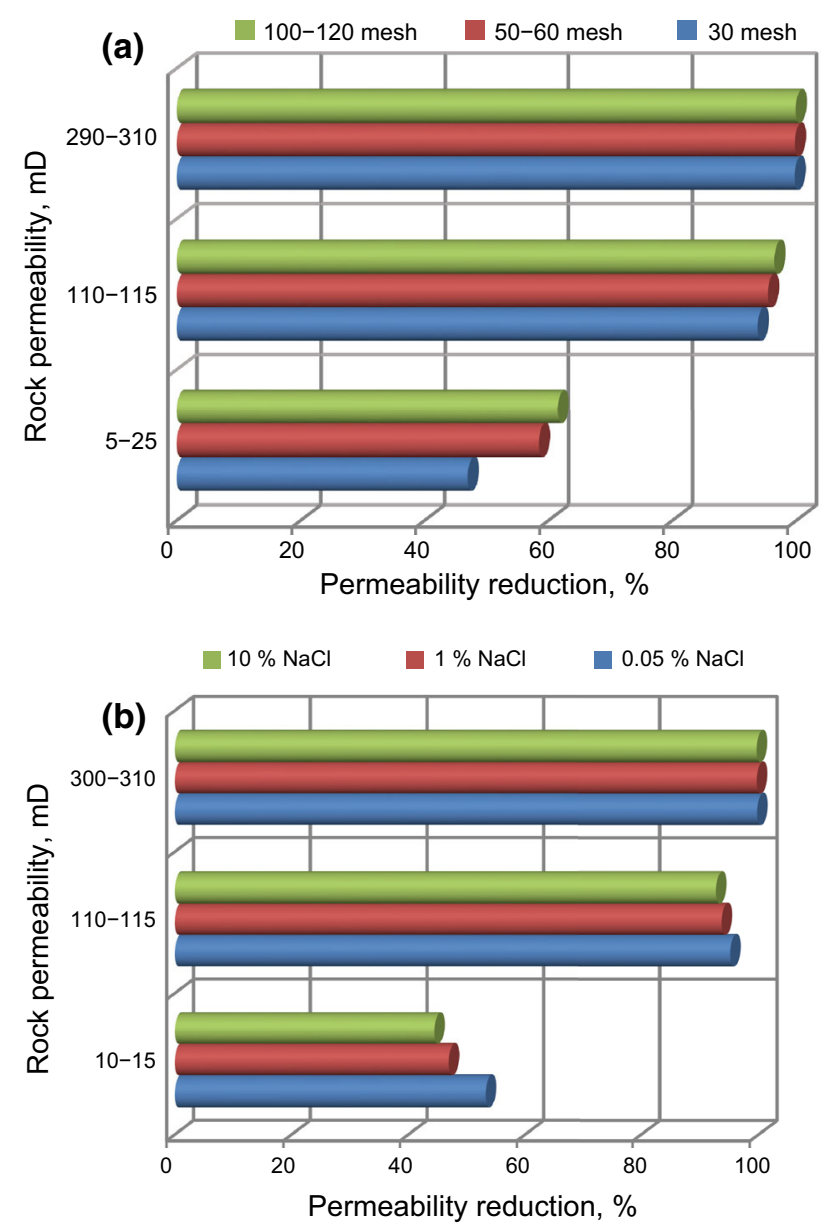

Fig. 8 Influence of sandstone rock permeability on load pressure results. a PPGs of different particle sizes (1\% brine). b Different $\mathrm{NaCl}$ concentrations (30 mesh PPG)

to various cores, the load pressure tests were needed. Table 6 displays the DQ gel effect on the core damage as well as the core permeability reduction. The core permeability was determined before and after the PPGs were compressed. These measurements were taken to find out the influence of the load pressure on the damage to sandstone core samples.

Figure 8 shows the influence of the particle gel size, rock permeability, and the $\mathrm{NaCl}$ concentration on the damage to sandstone core samples after being compressed with a piston. The load pressure was 300 psi. Figure 8a shows the influence of the particle size of PPGs on the core permeability. Smaller-sized particles damaged the cores more than the larger-sized particles. This is because the smaller-sized particles may enter further into the porous media, particularly high permeability cores. Figure $8 \mathrm{~b}$ shows the influence of $\mathrm{NaCl}$ concentration on the sandstone core permeability. The swollen PPGs prepared with solutions of higher $\mathrm{NaCl}$ concentrations decreased the core 
(a)

DQ gel (100-120 mesh)
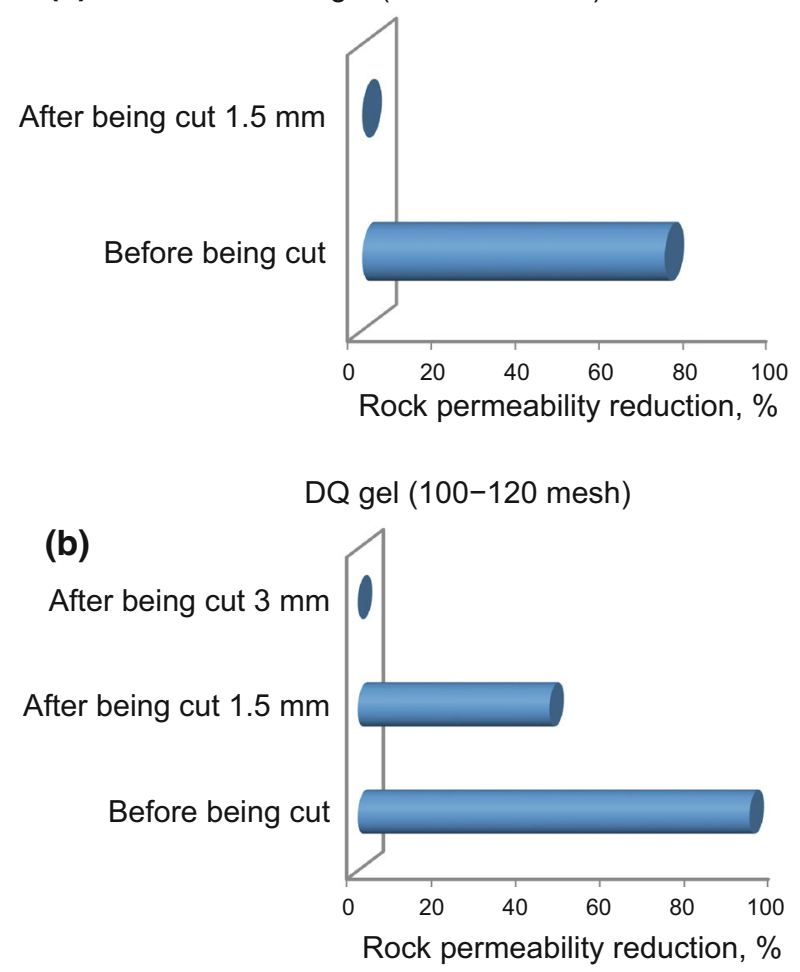

Fig. 9 Permeability reduction in sandstone core samples before and after the rock surface was cut. a $110-120 \mathrm{mD}$ core. b $290-310 \mathrm{mD}$ core

permeability less than PPGs prepared with solutions of lower $\mathrm{NaCl}$ concentrations. The gel strength of the PPGs with higher $\mathrm{NaCl}$ concentrations was higher than that prepared with lower $\mathrm{NaCl}$ concentrations. Figure 8 shows that in high permeability cores, PPGs damaged the cores further.

\subsection{Damage removed from the surface of sandstone rocks}

After each load pressure experiment the damage was removed by cutting a slice or slices from the core surface first, $1.5 \mathrm{~mm}$ and then to $3 \mathrm{~mm}$. This would remove the damage on the core surface and would not affect the core permeability of the non-damaged area since the core was fixed inside the round tube using two O-rings and a heavy duty glue. The core was cut with a sharp steel cutter which scratched the core surface many times until the core damage was removed. The purpose of cutting the core surface was to determine the penetration of the DQ gel into the core. This study included evaluating the effect of 100-120 mesh of DQ gel on the core permeability. The core permeability was determined after being cut. Figure 9 displays the reduction in the core permeability before and after each cut for the sandstone cores with permeabilities of
$110-120 \mathrm{mD}$ and $290-310 \mathrm{mD}$, respectively. Zhang and Bai (2011) found that the swollen gel particles will propagate through porous media of super high permeability. Elsharafi (2013) used a quantitative analytical model to determine the formation damage in the low permeable zones/areas.

PPGs penetration into the core surface was proved after removing the core damage by cutting the surface of the cores. The gel penetration was only a few millimeters even if a PPG of small particle size (100-120 mesh) was used. After the core permeability was measured, it was found that the core permeability returned to its original value when the damage removed. Thus, the PPG could not propagate through cores of permeability $<310 \mathrm{mD}$. In these cases, as shown in Fig. 10, PPGs were found to form an internal filter cake or an external filter cake (Azizi et al. 1997). On the sandstone core surface, an external filter cake was created (Fig. 10a). When PPGs propagated a few millimeters into the rock surface, an internal filter cake was created (Fig. 10b). In this work, there was no deep penetration of PPGs from the surface of sandstone cores (Fig. 10c). Hence, PPGs cannot transmit from side to side of sandstone cores while the ratio of particle size of PPGs to pore throat size is greater than 17 for reservoir formations with rock permeability $<310 \mathrm{mD}$. Core damage was also dependent on the pore size. The damage increased if the pore throat size increased in high permeability rocks.

\section{Comparison between weak (LiquiBlock ${ }^{\mathrm{TM}} 40 \mathrm{~K}$ ) and strong (Daqing) gels}

Elsharafi and Bai (2012) investigated the influence of weak PPGs on low permeable formations. A comparison between the effect of a strong gel (DQ gel) and a weak gel (LiquiBlock $^{\mathrm{TM}} 40 \mathrm{~K}$ gel) on rocks is significant to select the best PPG type for use in a specific mature reservoir. The chosen PPG should improve sweep efficiency and minimize formation damage.

\subsection{Filtration test results}

A comparison of filtration test results indicate that the DQ gels of 30-80 mesh are a good choice to protect low permeable formation from gel penetration. This gel would not damage low permeability cores (less than $25 \mathrm{mD}$ ) when no piston was used as it can be seen in Fig. 11a. Additionally, the permeability reduction caused by gels of 30,50-60, and 80 mesh was less than $2 \%$ while the core permeability was $110-115 \mathrm{mD}$ and $290-310 \mathrm{mD}$, respectively. In contrast, the particle gels of 100-120 mesh damaged the cores and reduced their permeability. Experimental results show that the weak gels with a low brine concentration are softer and 


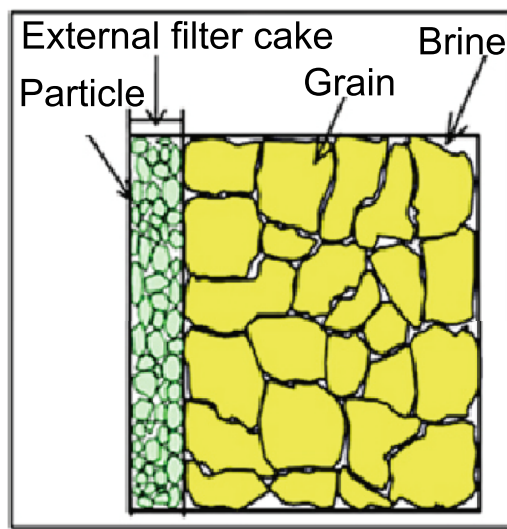

(a)

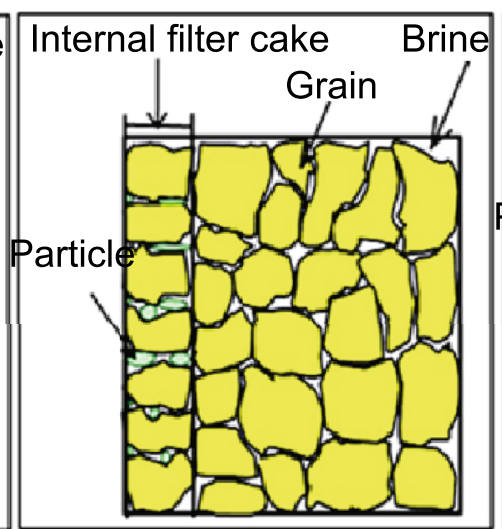

(b)

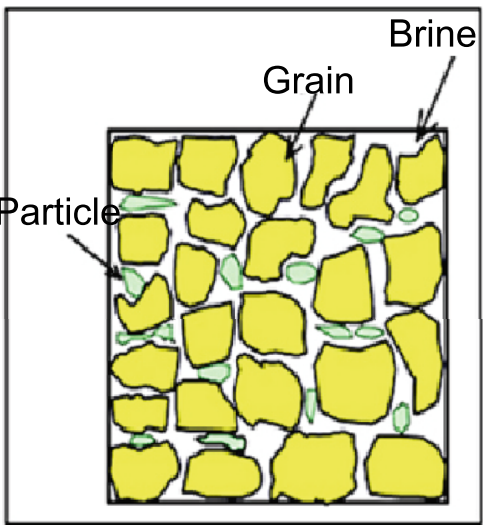

(c)

Fig. 10 Diagram of PPG damage. a PPGs form an external filter cake. b PPGs form an internal filter cake. c PPGs propagate in the core
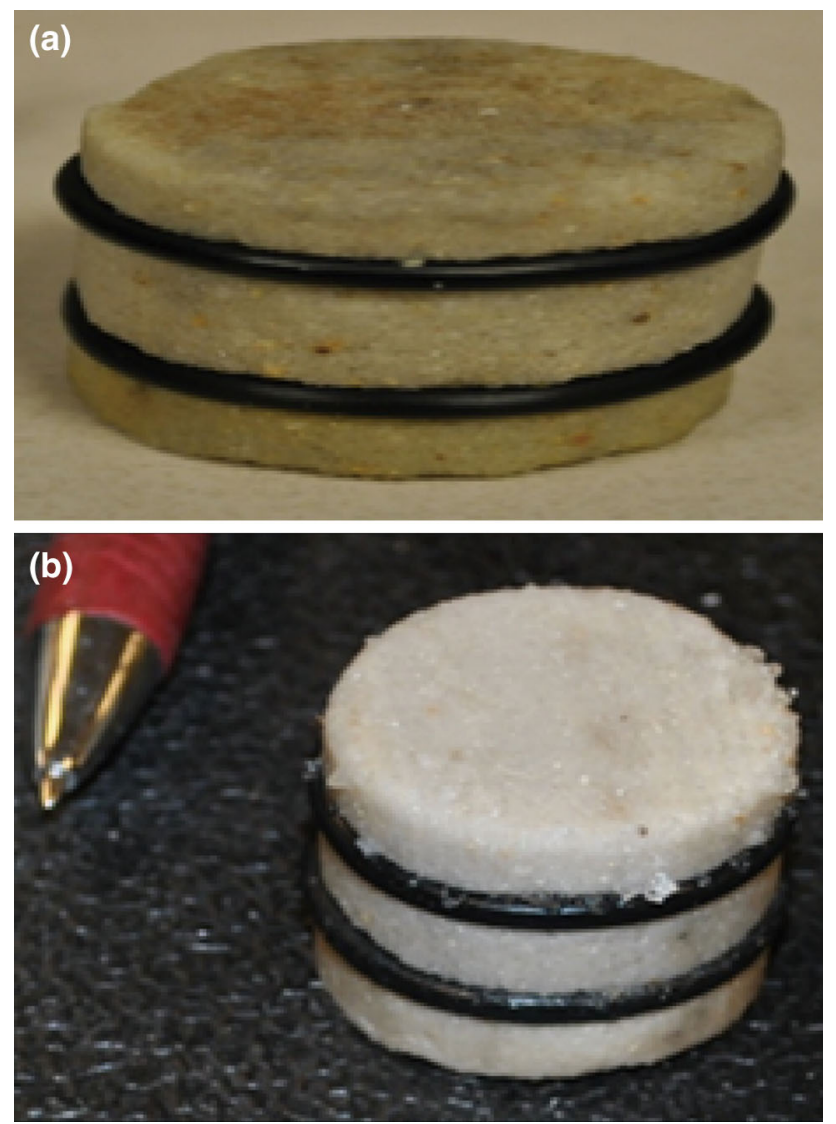

Fig. 11 Photos of the PPG effect on the core damage. a Not damaged (strong gel). b Damaged (weak gel)

more deformable than those with a high brine concentration. Therefore, low brine concentration caused more core damage. The weak gel damaged the formation more than the strong gel because the weak gel had less strength and compressed further than the strong gel. Figure $11 \mathrm{~b}$ shows a cake formed on the core surface when LiquiBlock ${ }^{\mathrm{TM}} 40 \mathrm{~K}$ gel was used. Figure 12 illustrates the initial core permeability (core permeability before the filtration test) versus the final rock permeability (after the filtration test) for both gels (LiquiBlock $^{\mathrm{TM}} 40 \mathrm{~K}$ gel, and DQ gel). LiquiBlock $^{\mathrm{TM}} 40 \mathrm{~K}$ gel of 30-120 mesh penetrated into the low permeable formations and decreased their permeabilities more than the DQ gel.

\subsection{Load pressure results}

The DQ gel, after being compressed by a piston, influenced core damage similar to the LiquiBlock ${ }^{\mathrm{TM}} 40 \mathrm{~K}$ gel. The compressed DQ gel also formed a cake on the core surface and decreased the core permeability. The core damage under the load pressure was higher than that under the filtration test because the PPGs were compressed more under the load pressure. As a result the pressure around the PPG pack inside the round tube and the pressure on the top of the core surface increased. Therefore, more particle gels penetrated into the core surface and caused further damage. The change from the initial rock permeability to the final rock permeability for LiquiBlock ${ }^{\mathrm{TM}} 40 \mathrm{~K}$ gel and DQ gels was depending on the particle size of gels, gel strength, and the original core permeability. Figure 13 shows the relationship between the initial core permeability and the final core permeability for LiquiBlockTM 40K and DQ gels. Figure 13 illustrates the final core permeability after PPGs were compacted by a piston for different permeability cores and PPGs of various particle sizes, respectively. A syringe pump with 300 psi injection pressure was used for LiquiBlock $^{\mathrm{TM}} 40 \mathrm{~K}$ and DQ gels. This load pressure reduced the core permeability more while using higher permeability cores for both gels. Both gels produced serious core damage and more permeability reduction when higher permeability cores were used. More damage occurred when higher permeability cores were used because higher permeability cores had larger pore throat 

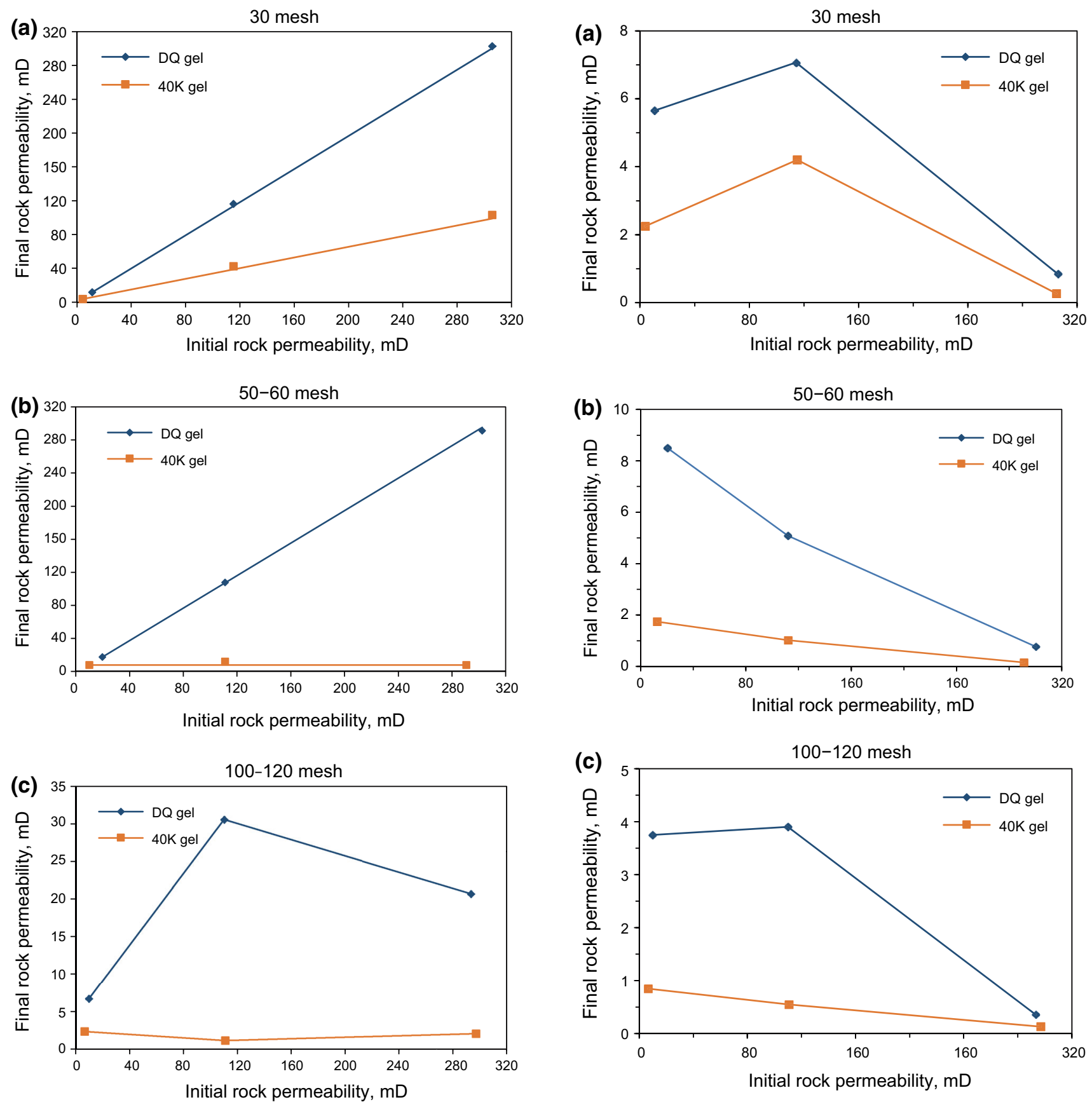

Fig. 12 Initial core permeability versus final rock permeability for both gels obtained from filtration tests. a 30 mesh PPGs. b 50-60 mesh PPGs. c 100-120 mesh PPGs

sizes which allowed PPGs to penetrate into the core surface and form a cake easier than lower permeability cores. In field applications, the strong gel causes less formation damage to the unswept, low permeable zones/areas than the weak gel. In addition, the formation damage of unswept, low permeability, oil-rich zones could be controlled by controlling the strength, type, and particle size of PPGs, and the brine concentration.

Fig. 13 Initial core permeability versus final rock permeability for both gels obtained from load pressure tests. a 30 mesh PPGs. b 50-60 mesh PPGs. c 100-120 mesh PPGs

\section{Conclusions}

(1) Filtration test results demonstrate that the strong DQ gel $(30,50-60$, and 80 mesh) did not damage low permeability cores of 5-25 $\mathrm{mD}$.

(2) The PPG did not propagate through sandstone cores and did not create a cake on the surface of sandstone cores. 
(3) The PPG damage to cores was influenced by the PPG size and the $\mathrm{NaCl}$ concentration; $100-120$ mesh DQ gel damaged low permeability cores $(5-25 \mathrm{mD})$ and the core permeability reduced by up to $32 \%$.

(4) Load pressure test results demonstrate that the PPG damage to cores was affected by the load pressure; more damage occurred when higher load pressure was applied.

(5) The PPG damage to cores was influenced by the rock permeability; more damage occurred when using sandstone cores of high permeability of 290-310 mD.

(6) A comparison between weak and strong gels shows that a strong gel is a better selection when considering formation damage protection.

Acknowledgments The authors would like to thank the Research Partnership to Secure Energy for America (RPSEA) for its financial support for this work. The authors want also to thank McCoy School of Engineering at Midwestern State University in Wichita Falls, Texas, United States; Petroleum Engineering Department at Missouri University of Science and Technology in Rolla, Missouri, United States; Petroleum Engineering Department at Sirte University, Libya; and Baker-Hughes for their support.

Open Access This article is distributed under the terms of the Creative Commons Attribution 4.0 International License (http://crea tivecommons.org/licenses/by/4.0/), which permits unrestricted use, distribution, and reproduction in any medium, provided you give appropriate credit to the original author(s) and the source, provide a link to the Creative Commons license, and indicate if changes were made.

\section{References}

Al-Abduwani FAH, Shirzadi A, Currie PK. Formation damage vs. solid particles deposition profile during laboratory simulated produced-water reinjection. SPE J. 2005;10(2):138-51. doi:10. 2118/112509-PA.

Al-Anaza HA, Sharma MM. Use of a $\mathrm{pH}$ sensitive polymer for conformance control. In: SPE international symposium and exhibition on formation damage control, February 20-21, Lafayette, LA; 2002. doi:10.2118/73782-MS.

Ali M, Currie P, Salman M. The effect of residual oil on deep-bed filtration of particles in injection water. SPE Prod Oper. 2009;24(1):117-23. doi:10.2118/107619-PA.

Al-Muntasheri G, Nasr-El-Din HA, Al-Noaimi K, et al. A study of polyacrylamide-based gels crosslinked with polyethyleneimine. SPE J. 2009;14(2):245-51. doi:10.2118/105925-PA.

Al-Muntasheri G, Zitha PL. Gel under dynamic stress in porous media: new insights using computed tomography. In: SPE Saudi Arabia section technical symposium, 9-11 May, Al Khobar, Saudi Arabia; 2009. doi:10.2118/126068-MS.

Al-Muntasheri G, Zitha PL, Nasr-El-Din HA. A new organic gel system for water control: a computed tomography study. SPE J. 2010;15(1):197-207. doi:10.2118/129659-PA.

Azizi T, Jin W, Rahman SS. Management of formation damage by improved mud design. In: SPE Asia Pacific oil and gas conference and exhibition, 14-16 April, Kuala Lumpur, Malaysia; 1997. doi:10.2118/38039-MS.
Bailey B, Crabtree M, Elphick J, Kuchuk F, et al. Water control. Oilfield Rev. 2000;12:30-51.

Bai B, Liu Y, Coste JP, et al. Preformed particle gel for conformance control: transport mechanism through porous media. SPE Reservoir Eval Eng. 2007a;10(2):176-84. doi:10.2118/89468-PA.

Bai B, Li L, Liu Y, et al. Conformance control by preformed particle gel: factors affecting its properties and applications. SPE Reservoir Eval Eng. 2007b;10(4):415-21. doi:10.2118/89389-PA.

Bai B, Huang F, Liu Y, et al. Case study of preformed particle gel for in-depth fluid diversion. In: SPE/DOE symposium on improved oil recovery, 20-23 April, Tulsa, Oklahoma; 2008. doi:10.2118/ 113997-MS

Bai B, Zhang H, Shuler $\mathrm{P}$, et al. Preformed particle gel for conformance control. Final report, RPSEA, Contract Number 07123-2; 2012. www.netl.doe.gov.

Chauveteau G, Omari A, Tabary R, et al. Controlling gelation time and microgel size for water shutoff. In: SPE/DOE improved oil recovery symposium, 3-5 April, Tulsa, Oklahoma; 2000. doi:10. 2118/59317-MS.

Chauveteau G, Omari A, Bordeaux U, et al. New size-controlled microgels for oil production. In: SPE international symposium on oilfield chemistry, 13-16 February, Houston, TX; 2001. doi:10.2118/64988-MS.

Coleman R, McLelland G. Produced water re-injection: how clean is clean?. In: SPE formation damage control symposium, 7-10 February, Lafayette, Louisiana; 1994. doi:10.2118/27394-MS.

Coste JP, Liu Y, Bai B, et al. In-depth fluid diversion by pre-gelled particles: laboratory study and pilot testing. In: SPE/DOE improved oil recovery symposium, 3-5 April, Tulsa, Oklahoma; 2000. doi:10.2118/59362-MS.

Dalrymple ED. Water control treatment design technology. In: SPE at the 15th world petroleum congress, 12-17 October, Beijing; 1997.

Elgmati M, Zhang H, Bai B, et al. Submicron-pore characterization of shale gas plays. In: SPE at North American unconventional gas conference and exhibition, 14-16 June, Woodlands, TX; 2011. doi:10.2118/144050-MS.

Elsharafi M, Bai B. Effect of weak preformed particle gel on unswept oil zones/areas during conformance control treatments. Ind Eng Chem Res. 2012;51(35):11547-54. doi:10.1021/ie3007227.

Elsharafi M. Minimizing formation damage for preformed particle gels treatment in mature reservoirs. Dissertation, Missouri University of Science and Technology; 2013.

Elsharafi M, Bai, B. Gel pack-a novel concept to optimize preformed particle gel conformance control treatment design. In: The 62nd southwestern petroleum conference, 22-23 April, Lubbock, TX; 2015. doi:10.2118/38039-MS.

Ershaghi I, Hashemi R, Caothien SC, et al. Injectivity losses under particle cake buildup and particle invasion. In: SPE California regional meeting, 2-4 April, Oakland, CA; 1986. doi:10.2118/ 15073-MS.

Frampton H, Morgan JC, Cheung SK, et al. Development of a novel waterflood conformance control system. In: SPE/DOE 14th symposium on improved oil recovery, 17-21 April, Tulsa, Oklahoma; 2004. doi:10.2118/89391-MS.

Gomaa AM, Mahmoud MA, Nasr-El-Din HA. Laboratory study of diversion using polymer-based in situ-gelled acids. SPE Prod Oper. 2011;26(3):278-90. doi:10.2118/132535-PA.

Gomaa AM, Nasr-El-Din HA. New insights into the viscosity of polymer-based in situ gelled acids. SPE Prod Oper. 2010;25(3):367-75. doi:10.2118/121728-PA.

Hong SD. Basics of reservoir petrophysics. Beijing: Petroleum Industry Publishing Company; 1985. p. 65-8 (in Chinese).

Hsi D, Dudzik S, Lane H, et al. Formation injectivity damage due to produced water reinjection. In: SPE formation damage control 
symposium, 7-10 February, Lafayette, Louisiana; 1994. doi:10. 2118/27395-MS.

Huh C, Choi SK, Sharma MM. A rheological model for $\mathrm{pH}$-sensitive ionic polymer solutions for optimal mobility-control applications. In: SPE annual technical conference and exhibition, 9-12 October, Dallas, TX; 2005. doi:10.2118/96914-MS

Huh CU, Choi SK, Shrman MM. pH sensitive polymers for novel conformance control and polymer flood applications. In: SPE international symposium oilfields chemistry, 20-22 April, Woodlands, TX; 2009. doi:10.2118/121686-MS.

James JS. Modern chemical enhanced oil recovery theory and practice. Houston: Gulf Professional Publishing; 2011. p. 101-206. doi:10.1016/B978-1-85617-745-0.00001-2.

Jia $\mathrm{H}, \mathrm{Pu} \mathrm{W}$, Zhao J, et al. Experimental investigation of the novel phenol-formaldehyde cross-linking HPAM gel system: based on the secondary cross-linking method of organic cross-linkers and its gelation performance study after flowing through porous media. Energy Fuels. 2011;25(1):727-36. doi:10.1021/ef101334y.

Juntail S, Abdoljalil V, Chun H, et al. Viscosity model of preformed microgels for conformance and mobility control. Energy Fuels. 2011a;25(1):5033-7. doi:10.1021/ef200408u.

Juntail S, Abdoljalil V, Chun H, et al. Transport model implementation and simulation of microgel processes for conformance and mobility control purposes. Energy Fuels. 2011b;25(1):5063-75. doi:10.1021/ef200835c.

Larkin R, Creel P. Methodologies and solutions to remediate innerwell communication problems on the SACROC $\mathrm{CO}_{2}$ EOR project: a case study. In: SPE/DOE symposium on improved oil recovery, 20-23 April, Tulsa, Oklahoma; 2008. doi:10.2118/ 113305-MS

Legemah M, Guerin M, Sun H, et al. Novel high-efficiency boron crosslinkers for low-polymer-loading fracturing fluids. SPE J. 2014;19(4):737-43. doi:10.2118/164118-PA.

Lei G, Li L, Nasr-El-Din H. New gel aggregates for water shut-off treatments. In: SPE improved oil recovery symposium, 24-28 April, Tulsa, Oklahoma; 2010. doi:10.2118/129960-MS.

Liu Y, Bai B, Wang Y. Applied technologies and prospects of conformance control treatments in China. Oil Gas Sci Technol. 2010;65(6):1-20. doi:10.2516/ogst/2009057.

Nemec R. Water, water everywhere in California oil production. NGI Shale Daily. 2014, Articles 99848. www.naturalgasintel.com.

Pritchett J, Frampton H, Brinkman J, et al. Field application of a new in-depth waterflood conformance improvement tool. In: SPE international improved oil recovery conference in Asia Pacific, 20-21 October, Kuala Lumpur, Malaysia; 2003. doi:10.2118/ 84897-MS.

Pyziak D, Smith D. Update on Anton Irish conformance effort. In: The 6th international conference on production optimizationreservoir-profile control-water and gas shutoff, 7-9 November, Houston, TX; 2007. doi:10.2118/103044-MS.

Rabie AI, Gomaa AM, Nasr-El-Din HA. Reaction of in situ gelled acids with calcite: reaction rate study. SPE J. 2011;16(4): 981-92. doi:10.2118/133501-PA.

Rabie AI, Gomaa AM, Nasr-El-Din HA. HCl/formic in situ-gelled acids as diverting agents for carbonate acidizing. SPE Prod Oper. 2012;27(2):170-84. doi:10.2118/140138-PA.

Reddy BR. Laboratory characterization of gel filter cake and development of nonoxidizing gel breakers for zirconium-crosslinked fracturing fluids. SPE J. 2014;19(4):662-73. doi:10.2118/ 164116-PA.

Rousseau D, Chauveteau G, Renard M, et al. Rheology and transport in porous media of new water shutoff/conformance control microgels. In: SPE international symposium on oilfield chemistry, 2-4 February, Houston, TX; 2005. doi:10.2118/93254-MS.

Roussennac B, Toschi C. Brightwater trial in Salema Field (Campos Basin, Brazil). In: SPE EUROPEC/EAGE annual conference and exhibition, 14-17 June, Barcelona, Spain; 2010. doi:10.2118/ 131299-MS.

Seright RS. Washout of Cr(III)-acetate-HPAM gels from fractures. In: SPE international symposium on oilfield chemistry, 5-7 February, Houston, TX; 2003. doi:10.2118/80200-MS.

Smith D, Giraud M, Kemp C, et al. The successful evolution of Anton Irish conformance efforts. In: SPE annual technical conference and exhibition, 24-27 September, San Antonio, TX; 2006. doi:10.2118/103044-MS

Sun Y, Wu Q, Wei M. Experimental study of friction reducer flows in microfracture. Fuel. 2014;131(1):28-35. doi:10.1016/j.fuel.2014.04. 050.

Sydansk RD, Xiong Y, Al-Dhafeeri AM. Characterization of partially formed polymer gels for application to fractured production wells for water-shutoff purposes. SPE Prod Facil. 2005;20(3):240-9. doi:10.2118/89401-PA.

Thomas FB, Bennion DB, Anderson GE. Water shut-off treatments reduce water and accelerate oil production. J Can Pet Technol. 2000;39(4):25-9. doi:10.2118/00-04-TN.

Veil JA, Puder MG, Elcock D. A white paper describing produced water from production of crude oil, natural gas and coal bed methane. Technical report prepared for National Energy Technology Laboratory (U.S DOE, under Contract No. W-31-109Eng-38), Argonne National Laboratory, Argonne, IL; 2004.

Vetter O J, Kandarpa V, Stratton M, et al. Particle invasion into porous medium and related injectivity problems. In: SPE international symposium on oilfield chemistry, 4-6 February, San Antonio, TX; 1987. doi:10.2118/16255-MS.

Wang Y, Bai B, Gao H, et al. Enhanced oil production through a combined application of gel treatment and surfactant huff'n' puff technology. In: SPE international symposium and exhibition on formation damage control, 13-15 February, Lafayette, Louisiana; 2008. doi:10.2118/112495-MS.

Wiedeman A. Regulation of produced water by the U.S. Environmental Protection Agency. In: Reed M, Johnsen S, editors. Produced water 2: environmental issues and mitigation technologies. New York: Plenum Press; 1996.

Wu Y, Tang T, Bai B, et al. An experimental study of interaction between surfactant and particle hydrogels. Polymer. 2011;52(2):452-60. doi:10.1016/j.polymer.2010.12.003.

Zaitoun A, Tabary R, Rousseau D, et al. Using microgels to shutoff water in gas storage wells. In: SPE international symposium on oilfield chemistry, February 28-March 2, Houston, TX; 2007. doi:10.2118/106042-MS

Zhang H, Challa R, Bai B, et al. Using screening test results to predict the effective viscosity of swollen superabsorbent polymer particles extrusion through an open fracture. Ind Eng Chem Res. 2010;49(23):12284-93. doi:10.1021/ie100917m.

Zhang H, Bai B. Preformed particle gel transport through open fractures and its effect on water flow. SPE J. 2011;16(2):388-400. doi:10. 2118/129908-PA.

Zitha PL, Darwish M. Effect of bridging adsorption on the placement of gels for water control. In: SPE Asia Pacific improved oil recovery conference, 25-26 October, Kuala Lumpur, Malaysia; 1999. doi:10.2118/57269-MS. 